\title{
THE PROTECTIVE EFFECT OF MALE ALBINO RATS TREATED WITH ANTIBIOTICS (COLCHICINE) (A HISTOLOGICAL STUDY)
}

\author{
DR:Nafisa Mohammed Batarfi \\ Biology Department \\ University of Jeddah, Jeddah, Saudi Arabia
}

\begin{abstract}
Colchicine: is a medicinal compound extracte from Colchicum autumnale plant flowers. It is used to treat gout, Behçet's disease, Mediterranean fever, psoriasis, cancer, and colitis. It has side effects that includes: diarrhea, nausea, vomiting, abdominal cramps, live function disorders, skin disorders, blood disorders, and effects on the formation of blood cells in the bone marrow leading to anemia, neurological effects, and fetal abnormalities (when used in pregnant women). And a decrease in the number of sperms, and may cause damage in some chromosomes and may lead to infertility and sterility, so the aim of the study was to know its effect on the reproductive channel of male rats.
\end{abstract}

Keywords - Colchicine, Leydig cells, Sertoli cells, Seminiferous tubules, Sperm, Epididymis.

\section{INTRODUCTION}

Antibiotics are used as a treatment for disease infections and have many harmful side effects that affect the body's systems. And some drugs have a highly effective effect on the reproductive system, in terms of imbalance of the microbial tubes in the testicle, Sertoli cells, low testicular weight, epididymis, and low sperm count. There are some antihistamines used to treat infections of the urinary system, respiratory system, intestine, treatment of malaria, and treatment of tuberculosis.

\section{MATERIALS AND METHOdS:}

Chemical name:

Colchicine; 64-86-8; Colchicin; Colchicina; Colchisol; Condylon

Chemical formula: $\mathrm{C}_{22} \mathrm{H}_{25} \mathrm{NO}_{6}$

\author{
Nada Allam \\ Biology Department \\ University of Jeddah, Jeddah, Saudi Arabia
}

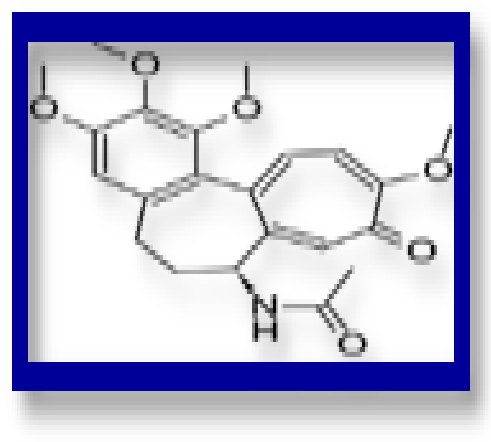

FIG. CheMicAl FORMULA

\section{EXPERIMENTAL ANIMALS}

The experiment was carried out on 30 of the Swiss male albino rat species, their weight ranges from 150-200 grams and divided into three groups.

The first group (Control): They are given food and water daily.

The second group: They treated with colchicine for a period of three weeks, (10 rats) colchicine is administered in a dose of 1 $\mathrm{ml} / 100 \mathrm{~g}$.

The third group: They treated with colchicine for a period of six weeks, (10 rats) with a dose of $1 \mathrm{ml} / 100 \mathrm{~g}$.

The rats were dissected, the genital tract was taken, and placed in a neutralized formalin stabilizer at a concentration of $10 \%$. Standard methods were used for dehydration, clearing and burial in paraffin wax. Cross sections with a thickness of 3 microns were made from the tissue of the controlled and treated samples, and stained with Hematoxylin \& Eosin (Bancroft \& Stevens, 1996). 


\section{RESUlTS}

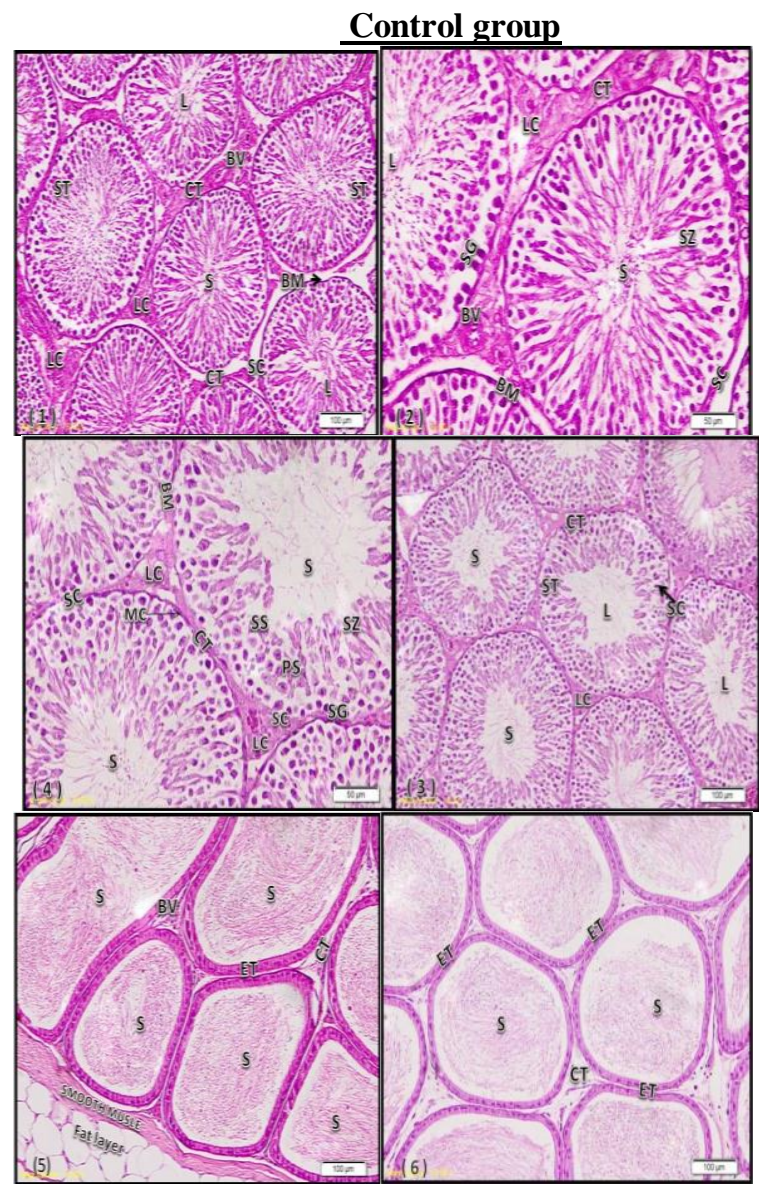

1. An optical microscope image showing a cross-section of the testicle in which the shape of the tubules appears in a circular shape and between them there are interfaces in which there are Leydig cells (LC) and the germ cell layers and Sertoli cells (SC) based on the basal membrane (BM) (H\&E X 100) appear.

2. An enlarged microscope image showing the layers and arrangement of germ cells and showing sperm (S) inside the lumen (L), and there is a blood vessel between sperm tubules (BV) (H\&E X 400).

3. A microscope image showing the structure of the seminal tube (ST) and the Sertoli cells (SC), as well as the presence of sperm (S) inside the lumen (L) (H\&E X100).

4. An enlarged microscope image showing the layers and arrangement of germ cells, where spermatogenic cells (SG) are based on the basement membrane of the tube (BM) and moiyd cells (MC), followed by primary sperm cells (PS), then secondary sperm cells (SS), and spermatids (SZ) and finally the Sperm (S) (H\&E X 400).

5. A cross-section image of the epididymis cross section showing a layer of smooth muscle surrounding the epididymal tubes consisting of a thick layer of cubic epithelial cells, and showing connective tissue between them (H\&E X100).

6. A microscope image showing the structure of the epididymis, the shape of the epididymis tubes, and their inner sperm (S) (H\&E X100).

\section{TRATMENT GROUP}

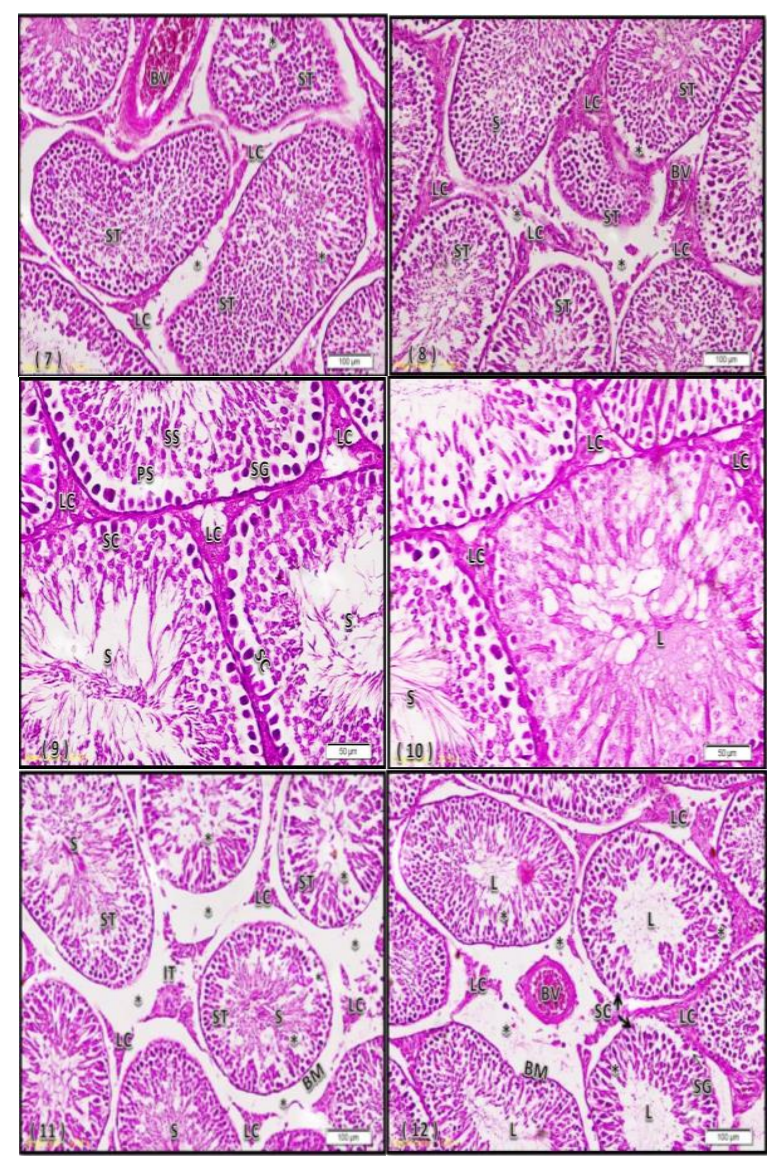

7. An optical microscope image showing histological changes in the cross-section of the testicle, where germ cells denote, sperm tube distortion (ST), bloody stagnation (BV), and amplitude of intermittent distances in the tubules $(*)$ (H\&E X100).

8. A cross section of the testicle that shows seminal tubules and shows clear degeneration of Leydig cells (LC), germ layer separation from the basal membrane (BM) and spermatogenesis (S) (H\&E X100).

9. An enlarged image of a cross-section of the testicle shows a clear degeneration of germ cells in seminal tubules, increased cavity amplitude, sperm death and sperm destruction (S) (H\&E X400).

10. An enlarged image of a cross-section of the testicle that shows increased amplitude of interfaces, 


\section{International Journal of Engineering Applied Sciences and Technology, 2020 \\ Vol. 4, Issue 11, ISSN No. 2455-2143, Pages 17-23 \\ Published Online March 2020 in IJEAST (http://www.ijeast.com)}

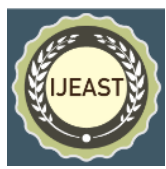

increased Lysis of Leydig cells (LC), and the appearance of diffuse foci in the seminal tubules (ST) (H\&E X 400).

11. A cross section of the testicle shows deformation of cells in tubules, foci appearing, increasing amplitude of distances between tubules and changing their shapes (H\&E X 100).

12. A cross section of the testicle, increased tubular form deformity, increased vascular congestion, blood stasis, and disappearance of Leydig cells (H\&E $\mathrm{X} 100)$.

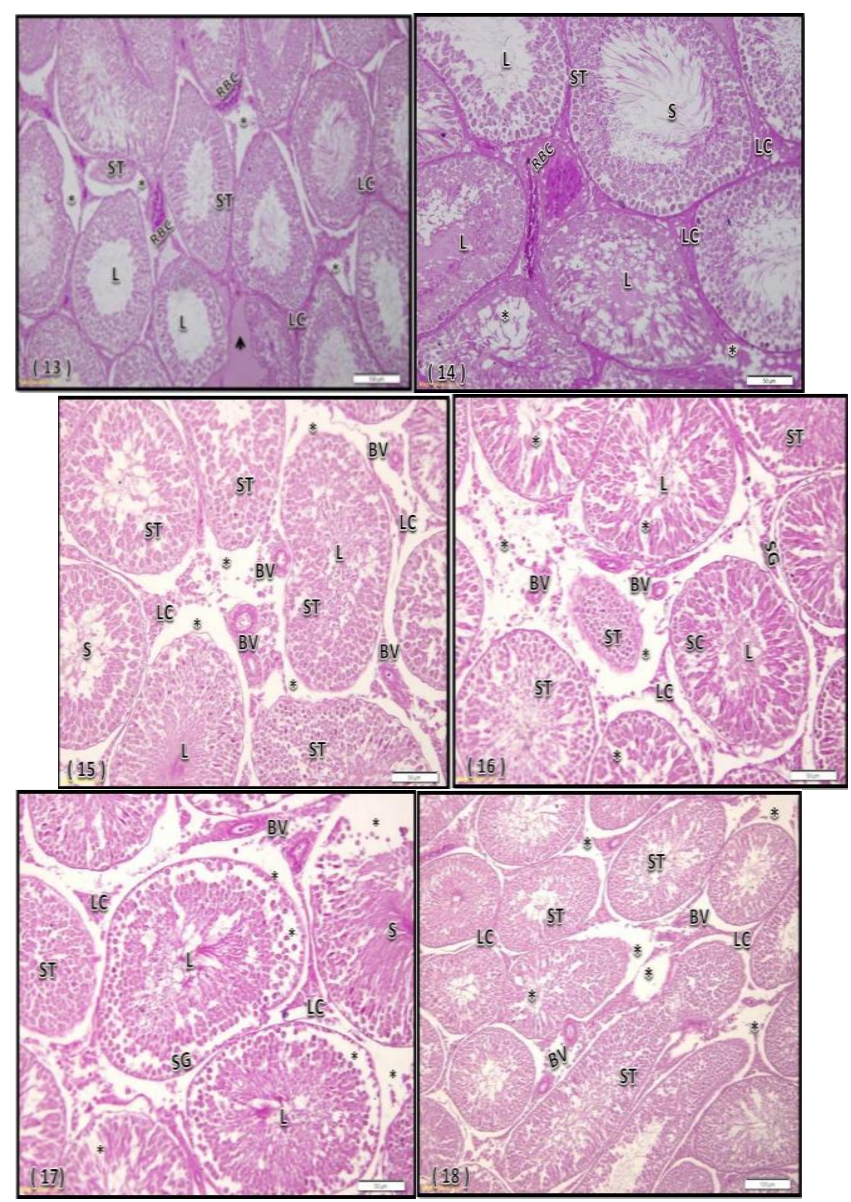

13. A cross section of the testicle shows a clear hematoma transfusion between the seminal tubules, a pronounced atrophy of the seminal tubules, an increase in the amplitude of the cavity inside the tubules, a decreased sperm presence (S) and a blood stasis (H\&E X100).

14. A cross section of the testicle shows increased amplitude between the seminiferous tubules (*), apparent blood stasis RBC and germ layer separation (H\&E X 100).

15. A cross section of the testicle shows a clear change in the shape and length of the seminiferous tubules, necrosis and death of germ cells, blood vessels (BV), and decreased cavity within the seminal tubules (H\&E X 100).

16. A cross section of the testicle shows the dissolution of the wall of the seminiferous tubules, the increase in the amplitude of the interface distances, the separation of the bacterial layer from the epithelial and atrophies in the form of some seminal tubules (H\&EX 100).

17. A cross-section of the testicle demonstrates acute deformation of the seminiferous tubules, desquamation of the plasma cells, spermatogenesis in the tubules and Leydig cell lysis (H\&E X 100).

18. A cross section of the testicle that shows increased elongation of seminal tubules, foci and interstitial spaces (*), and vascular congestion (H\&E X100).

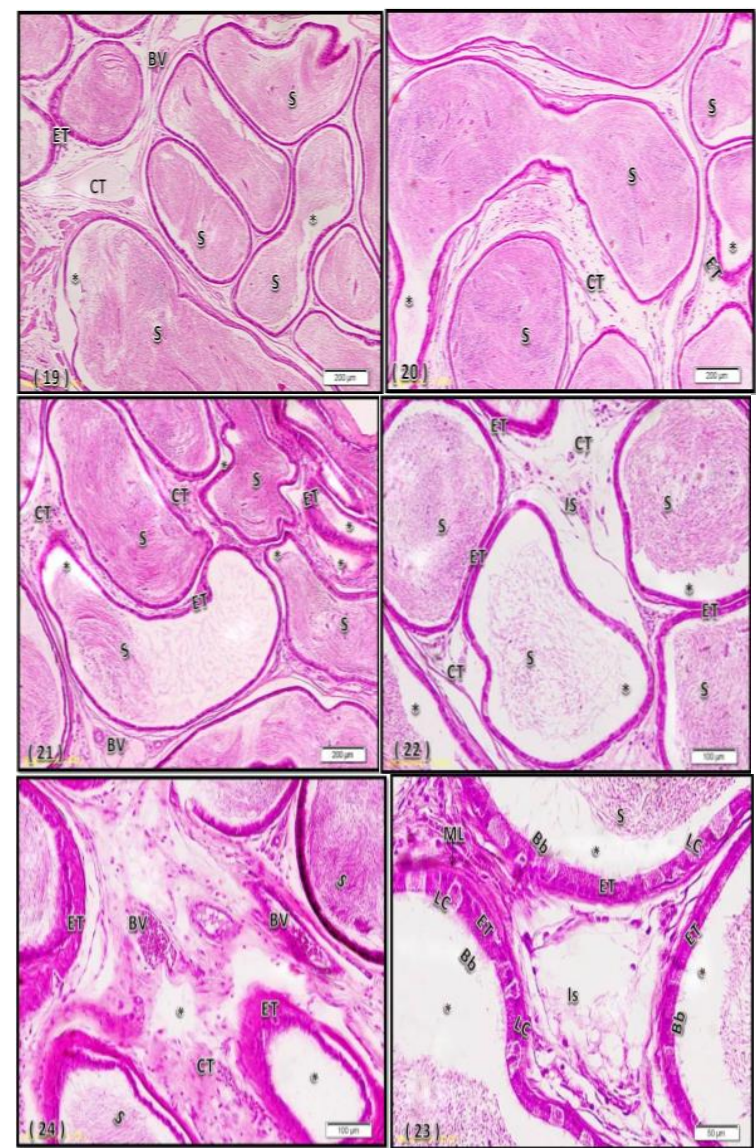

19. A cross section of the epididymis tail shows a change in the epididymis, wall thickness, sperm exfoliation (S) within the cavity, and abnormalities in interstitial cells (H\&E X100).

20. Cross section in epididymis showing severe deformities in epididymis tubes, wall thickness and increased interconnection (*) (H\&E X100). 


\section{International Journal of Engineering Applied Sciences and Technology, 2020 \\ Vol. 4, Issue 11, ISSN No. 2455-2143, Pages 17-23 \\ Published Online March 2020 in IJEAST (http://www.ijeast.com)}

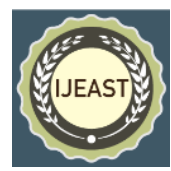

21. A cross section of the epididymis shows the decrease and the thickness of the epididymis wall (H\&E $\mathrm{X} 100)$.

22. A cross section of the epididymis, showing the widening of the spacing and the lack of sperm (S) within the epididymis tubes (H\&E X100).

23. An enlarged cross-sectional image of the epididymis showing small cubic epithelial cells and a damaged brush (BB). The degeneration of the muscle layer (ML) and sperm count (S) were also observed. And the width of the interstitial tissue (IS) (H\&E X400).

24. A cross section of the epididymis shows deformation of the tube shape and its sperm-free (S) (H\&E X100).

\section{RESULTS AND DISCUSSION}

Colchicine causes sperm malformations and sperm malfunction. The sperm malformations in the testicle and epididymis include deformation of the shape of the head.

The examination of the testicles of rats showed an expansion of blood vessels by the inter-tissue, proliferation of the inner coating of the lining, blood stasis and congestion of the vessels (BV) homogeneous pigmentation with eosin and the dissolution of cells leading to in some places the intertissue; with the appearance of some circular seminal vids in some of them, while others are observed to contract. Where tubules lose the spherical or oval shape and the interstitial space widens between them with loss of bacterial cells in them, and some sperm cells are denounced where the cytoplasm pigmentation intensifies with homogenization of eosin and the number of Sertoli cells associated with the basal membrane decreases compared to the control group; bacterial cells may decompose where a clear deficiency is observed and spatial decomposition Sertoli and seminiferous shrinkage and membrane thickness increases.

The examination showed that sperm tubules increased in size and the appearance of mutant spermatids and spermatozoa in the tube of the tubules, although a sharp decrease in their number was observed compared to the control group. As the tubules diverged, cellular leaching was observed in the interstitial tissue, and a few size and Leydig cells appeared beside the broken tubules, while an increase in size and filling in the gaps were observed alongside the natural tubules. It demonstrates focal decomposition, sperm deformation, and erosion of Sertoli cells, while semen mothers and Sertoli cells are associated with the basal membrane of tubules, and it shows increased susceptibility to healthy pigment cells, while susceptibility to pigmentation is significantly reduced in damaged germ cells. This is consistent with what has been seen from the degradation of Sertoli cell tubes by colchicine by (Wolosewick \& Bryan 1977).

Varieties of abnormalities have been observed in Sertoli cells, including disorganization of normal connections and severe apical distension in the lumen. This last loss of cell shape was so widespread that in some cases the normal structure of the seminal epithelium was disrupted and the cavity was blocked. A reasonable change in the cell shape can be attributed to the deterioration of the microtubules in Sertoli cells.

The testicle of rats treated with colchicine after four days of treatment showed moderate degeneration of sperm cells. Sperm debris can be detected in the cavity of the sperm tubes. In seven days, the testicle suffered interstitial edema with signs of fatty degeneration and degeneration of sperm cells that line some seminal tubes. Also, complete destruction with a lack of cells in the seminal layers in some seminal tubules.

Others only contained germ cell residues with disrupted sperm cell nuclei with the emergence of giant cells with a very low number of Leydig cells containing mutilated nuclei. This is consistent with Bumbasirevie et al. (1996), where it was stated that colchicine led to programmed cell death, and that quantitative results indicate that hyperchromia may be due to a high amount of chromatin within the nucleus high in colchicine-treated samples. On the other hand, the testicle showed a severe decrease in the number of Leydig cells, changes in the seminal cells lining the seminal serous tubes, and the appearance of giant sperm cells. Days later, complete destruction of the sperm cells occurs. Sperm residues can be detected in the cavity of the seminal tubes. (Allard et al. 1993).

It was also found in some sectors to expand and distort the tubules and the expansion of the cavities and free them from the sperm hypospermatogenesis and the emergence of some dead cells in the cavity of the tubes with a clear deficiency in the vital content, and the small, highly pigmented Leydig cells appeared. In other sectors, it is observed that the testicular maturity is not complete, as sperm tubes appear small with narrow cavity and free of sperm, and mutilated and deformed mutant precursors appear and a few, small and unrecognized Leydigs cells.

The testicular toxicity is inferred, with evidence of bacterial cell separation and removal 1 hour after treatment (Lim, J., and Miller, M. G. 1997). It lasts for several hours.

In this study, the seminal epithelialization was undamaged and in conformity with the controls; and the characteristic of the microparticular extensive tube network of Sertoli cells was intact, consistent with histological findings. On the contrary, it was discovered that the cell structure of Sertoli cell rats suffers from severe post-treatment disorder (Hess and Nakai 2000). , testicular sections of the testis appeared normal except that the cavity in the spermatic tubes was larger than in the control since colchicine was injected directly into the testis of rats (Friedman, PA, and Platzer, EG 1978; \& Ireland, et. al 1979).

\section{Epididymis:}

A decrease in the fertility rate or sperm motility was observed in male rats that dealt with colchicine during the trial period. The examination of the sectors showed a decrease in 


\section{International Journal of Engineering Applied Sciences and Technology, 2020 \\ Vol. 4, Issue 11, ISSN No. 2455-2143, Pages 17-23 \\ Published Online March 2020 in IJEAST (http://www.ijeast.com)}

the diameter of the duct and its sperm content and its comparison with the control, and its normal coating in some sectors, while increasing the epithelial thickness of the epididymis and the increase of the granules Positive for pigmentation in clear cells and increase the thickness of the basal membrane and its susceptibility to pigmentation and free of sper m. .

The tissue damage to the epididymis channel in the high-dose rats (G3) is intensified, and the degradation of the intervertebral tissue, the irregularity of the epididymis surface, the intensity of apical cytoplasm pigmentation and the purpinal margin, and the presence of dead germ cells within the cavity are noted. Where the tubules lose the spherical or oval shape and the interstitial space widens between them with the loss of germ cells in them, and some sperm cells deny where the pigmentation of the cytoplasm increases with homogeneity of the eosin, and the number of Sertoli cells associated with the basal membrane decreases compared to the control group; and the bacterial cells may break down where a clear deficiency is observed with Gap decomposition with Sertoli cells. This is consistent with (Pholpramool, C., and Srikhao, A. 1983). As the target organ is not only the testicle, which is the main organ of sperm, but also epididymis, where sperm maturation occurs. Some studies have shown a decrease in the concentration of sperm and motility in rats (Horimoto et. Al. 2000; Sharma, R. K., and Kalla, N. R. (1994). However (Hoyt et al. 1995) indicated that sperm concentrations decrease and movement changes, and the main causes of infertility due to fertility impairment and reduced sperm and motility concentrations may not change (O'Morain et. Al. 1985). On the other hand, (Sharma, R. K., and Kalla, N. R. 1994) reported greater surface abnormalities in the sperm of rats. And many cellular residues and bacterial cells exfoliating inside the cavity and the intensity of epithelial pigmentation, epididymitis and interstitial tissue. A decrease in the size of the epididymis canal was observed compared to the control and its sperm content. It shows a focal increase in the epididymis sections of the nail and the number of cells in it, the fracture of the purpinal margin, and the epithelial cell exfoliation and its eruption of the cavity; where the cavity contains few sperms. And as it shows focal deformity in some sectors of epididymis, the intensity of homogeneous pigmentation, the lack of distinction of cell boundaries, the destruction of clear cells and the lack of their granular content, few healthy sperms, and deformed cavities.

(Das UK et. Al. 2009) presented a similar report in mice, which confirmed this decrease in testosterone levels and was able to determine the mechanism of intervention in the hormone synthesis process in the Leydig cells. Bacterial results showed that the 30-day treatment of mice with colchicine caused a significant decrease in sperm motility. A similar report was presented by (Verma PK et. Al. 2002) in mice treated with extract. This indicates that tetracycline was able to permeate the testicular barrier with resulting changes in the microenvironment of the seminal tubules; Where it was reported that the decrease in sperm motility caused by chemical factors is due to its ability to permeate blood, (Baldessarini RJ. 1980) thus creating a different microenvironment in the inner part of the sperm tube wall than that in the outer part Bloom (W, Fawcett DW. 1975). Epididymal functions or testosterone activities work by the secretion of the pituitary gland, the frontal lobe responsible for the gonads that may alter sperm (William KW. 2000; Bowman WC, Rand MJ. 1985) and causes a significant decrease in the number of sperms. For treated rats that may be the result of low plasma levels of testosterone since this hormone has been reported to be important in initiating and forming sperm (Christensen AC 1975).

\section{$\underline{\text { Recommendations: }}$}

1. Not to use antibiotics without medical advice.

2. Increased awareness and health education in the use of medications.

3. Knowledge of the harmful effects and risks of antibiotics and their reproductive health.

4. There is still extensive research on the importance of antibiotics and their harm to society.

\section{REFERENCE}

1. Allard, E.K.; Johnson, K.J. and Boekelheid,K. (1993): Colchicine disrupts the cytoskeleton of rat testis seminiferous epithelium in a stage-dependent manner. Biol. Reprod., 48(1):143-153.

2. Baldessarini RJ (1980): In drugs and the treatment of psychiatriod disorders. The pharmacological basis of therapeutics Ed. By Goodman and Gilman. Macmillan Pub. Co. Inc. pp. 301-417.

3. Bancroft, 1996 J.D. BancroftProteins and nucleic acids J.D. Bancroft, A. Stevens (Eds.), Theory and Practice of Histological Techniques (fourth ed.), Churchill Livingstone, London (1996), pp. 237-238

4. Bloom W, Fawcett DW (1975): Male reproductive system. In the textbook of Histology. Saunders Company, Philadelphia.

5. Borron, S.W.; Scherrmann, J.M. and Baud, F.J. (1996): Markedly altered colchicine kinetics in a fatal intoxication: Examination of contributing factors. Hum. Exp. Toxicol., 15:885-890.

6. Bowman WC, Rand MJ (1985): The reproductive system and drugs affecting the reproductive systems. Textbook of pharmacology, 2nd edition, 20:1-8. 


\section{International Journal of Engineering Applied Sciences and Technology, 2020 \\ Vol. 4, Issue 11, ISSN No. 2455-2143, Pages 17-23 \\ Published Online March 2020 in IJEAST (http://www.ijeast.com)}

7. Bumbasirevie, V.; Scaro-Milic, A.; Mireie, A. and Djurieie, B. (1996): Apoptosis induced by microtubule disrupting drugs in normal murine thymocytes in vitro. Scanning Microscope, 9: 509-516.

8. Christensen AC (1975): Leydig cell: In: Handbook of Physiology, edited by P.O. Greep and E.B. Astwoods. Washington D C American Physiological Society.

9. Cohen, A.S.; Rubinov, A.; Anderson, J.J. (1987): Survival of patients with primary amyloidosis: Colchicine-treated cases from 1976-1983 compared with cases seen in previous years. Am. J. Med., 82:11821190.

10. Das UK, De D, Chatterjee K, Mallick C, Bera TK, Ghosh D (2009): Antigonadal effect induced by hydromethanolic extract of leaf of Aelgle mermelos in male rat: Effect of hCG co-administration. Journal of Medicinal Plants Research Vol. 3(10), Pp728 - 735.

11. Dooher, G. B. \& BENNETT, D. (1973). Fine structural observations on the development of the sperm head in the mouse. Am. J. Anat. 136, 339-362.

12. Friedman, P. A., and Platzer, E. G. (1978). Interaction of anthelmintic benzimidazoles and benzimidazole derivatives with bovine brain tubulin. Biochim. Bioph. Acta 544, 605-614.

13. Hess, R. A., and Nakai, M. (2000). Histopathology of the male reproductive system induced by the fungicide benomyl. Histol. Histopathol.15, 207-224.

14. Horimoto, M., Isobe, Y., Isogai, Y., and Tachibana, M. (2000). Rat epididymal sperm motion changes induced by ethylene glycolmonoethyl ether, sulfasalazine, and 2,5-hexandione. Reprod. Toxicol.14, 55-63.

15. Hoyt, J. A., Fisher, L. F., and Swisher, D. K. (1995). Short-term male reproductive toxicity study with sulfasalazine in the rat. Reprod. Toxicol.9,315-326.

16. Ireland, C. M., Gull, K., Gutteridge, W. E., and Pogson, C. I. (1979). The interaction of benzimidazole carbamates with mammalian microtubule protein. Biochem. Pharmacol.28, 2680-2682.

17. Ireland, C. M., Gull, K., Gutteridge, W. E., and Pogson, C. I. (1979). The interaction of benzimidazole carbamates with mammalian microtubule protein. Biochem. Pharmacol.

$$
\text { 28, 2680-2682. }
$$

18. Joshi, H.C. (1998): Microtubule dynamics in living cells. Curr. Opin. Cell Biol., 10:35-44.
19. Kaplan, M.M.; Alling, D.W.; Zimmerman, H.J. (1986): A prospective trial of colchicine for primary biliary cirrhosis. N. Engl. J. Med., 315:1448-14454.

20. Kershenobich, D. (1988): Colchicine in the treatment of cirrhosis of the liver. N. Engl. J. Med., 318: 1709-1713.

21. Lim, J., and Miller, M. G. (1997). The role of the benomyl metabolite carbendazim in benomyl-induced testicular toxicity. Toxicol. Appl. Pharmacol.142, 401410.

22. Markland, O.N. (1971): Ultrastructural changes in skeletal muscle induced by colchicine. Arch. Neurol., 24:72-82.

23. Naidus, R.M.; Rodiven, R.; Mielke, C.H. (1977): Colchicine toxicity. A multisystem disease. Arch. Intern. Med., 137:394-396.

24. Oakberg, E. F. (1956). A description of spermiogenesis in the mouse and its use in analysis of the cycle of the seminiferous epithelium and germ cell renewal. Am. J. Anat. 99, 391-413.

25. O'Morain, C. O., Smethurst, P., and Levi, A. J. (1985). Reversible male fertility induced by sulphasalazine. In Male Fertility and its Regulation (Lobet, T. J. and E. S. E. Hafez, Eds.), pp. 49-54. Kluwer Academic Publishers, The Netherlands.

26. Pholpramool, C., and Srikhao, A. (1983). Antifertility effect of sulfasalazine in the male rat. Contracepetion 28, 273-279.

27. Sharma, R. K., and Kalla, N. R. (1994). Spermatozoal abnormalities and male infertility in the rat following sulfasalzine treatment. Int. J. Fertil. Menopausal. Stud. 39, 347-354.

28. Stahl, N.; Weinberger, A. and Benjamin, D. (1979): Fatal colchicine poisoning in a boy with familial Mediterranean fever. Am. J. Med. Sci., 278:77-81.

29. Stemmermann, G.N. and Hayashi, T. (1971): Colchicine intoxication. A reappraisal of its pathology based on a study of three fatal cases. Hum. Pathol., 2:321-332.

30. Verma PK, Sharma A, Annu M, Prachi S, Gupta RS, Joshi SC, Dixit VP (2002): Effect of Sarcostemma acidum stem extract on spermatogenesis in male albino rats. J. Androl. 4(1): 43 - 47. 
31. William KW (2000): Hormones and Hormone antagonists. In: Remington, The Science and Practise of Pharmacy, vol 11, 20th edition 77: 1390-1391.

32. Wolosewick, J. J. \& BRYAN, J. H. D. (1977). Ultrastructural characterization of the manchette microtubules in the seminiferous epithelium of the mouse. Am. J. Anat. 150, 301-332.

33. Zemer, D.; Revach, M. and Pras, M. (1974): A controlled trial of colchicine in preventing attacks of familial Mediterranean fever. N. Engl. J. Med., 291:932-9 